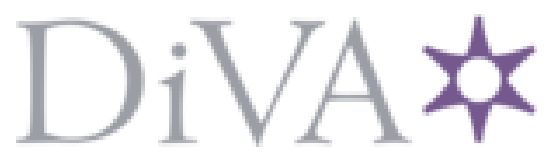

http://www.diva-portal.org

\title{
Postprint
}

This is the accepted version of a paper published in International Journal of Older People Nursing. This paper has been peer-reviewed but does not include the final publisher proofcorrections or journal pagination.

Citation for the original published paper (version of record):

Hedman, K. (2019)

Strengths and support of older people affected by precarity in South Louisiana

International Journal of Older People Nursing, 14(2): e12232

https://doi.org/10.1111/opn.12232

Access to the published version may require subscription.

N.B. When citing this work, cite the original published paper.

Permanent link to this version:

http://urn.kb.se/resolve?urn=urn:nbn:se:hj:diva-42897 


\title{
Strengths and Support of Older People Affected by Precarity in South Louisiana
}

\section{Karl Hedman}

\begin{abstract}
:
Background. Few empirical studies have examined strengths and support of older people in circumstances of precarity. A better understanding of this problem has the potential to contribute to the development of care planning and delivery.

Purpose. To investigate how older people deal with episodes of precarity in South Louisiana.

Method. More than 300 hours of participant observation and interviews were conducted with 20 predominantly older African American women in a housing complex for low-income older persons and two senior citizen centers.

Results. The findings demonstrate five central negative conditions of precarity that older people had to manage: (1) loss and discontinuity of home-based health care services, (2) stress after loss or disruption of social support, (3) problems of poverty, (4) cognitive impairment and declining health, and (5) stress of eviction. Strengths and support that older people used were as follows: (1) spiritual faith, (2) psychological strengths, (3) spiritual relationships, (4) family support, (5) friendships of love and friendships of helpfulness, (6) care and support performed by home-based services, (7) senior center and housing complex activities, (8) church memberships and activities, and (9) grocery store and café contacts.

Conclusion. Home-based services were not sufficient to prevent and reduce precarity for older people because of a lack of and discontinuities in these services.

Implications for practice. This study adds to the literature about precarity among communitybased older people by demonstrating gaps in care support and medication access. The findings suggest that ongoing state funding and support by home-based services are necessary to support frail older people in precarious living conditions to survive and handle stressful life events by reducing vulnerability and enhancing strengths and supportive resources of older people.
\end{abstract}




\section{SUMMARY STATEMENT}

\section{Research contribution to existing knowledge in gerontology}

This investigation identifies gaps and discontinuities of home-based health care services including nursing care as well as problems with obtaining medications and the residential security of older people in conditions of precarity. Results from this project provide insight into how older people deal with these situations. Spiritual faith and friendships stand out as the most central strengths and supportive resources of the older people in contrast to the discontinuity of housing support and home-based health care services.

\section{Implications for nursing care with older people}

Ongoing nursing care support and medication access without gaps are needed to protect against precarity of older people. Once older people receive help through nursing care, they can slip back into precarity because of gaps in the care. Here continuity in care is important to reduce or eliminate those gaps.

\section{How the findings could be used to influence policy, practice, research or education}

The findings could be used to provide ongoing state funding and support by home-based services to help frail older people, simplify for older persons to have personal assistants and promote friendships between older people through programs in community centers. This study provides arguments regarding public policy that older people should be able to stay because the buildings for low-income older people receive federal funding. The investigation demonstrates that the threat of eviction for older persons in low-income housing exists even with the presence of federal funding for these buildings.

It is vital to maintain residential security and prevent eviction and homelessness of older people supporting older persons in place or helping them to be relocated to new homes in case they are evicted to maintain long-term health, care and stability for older people. One measure is to have post-eviction care specifically designed for older people through starting and funding shelters to house and feed older people. These shelters should provide help to older people to do paper work and make calls to sign up for new housing. Another measure is to have funding to provide legal services for older people to prevent them from being evicted and have informational campaigns to inform older people, leaders and boards of senior housing complexes about the legal rights of older persons. 


\section{Introduction}

Answering the question of how older people manage circumstances of precarity is an important problem faced in society. From a legal perspective, older people and their human rights is one of the most current issues in research today (Sabatino, 2018), yet little is known about this issue mainly because there has been a scarcity of research performed on the human rights of older people in relation to their protective strengths and support in precarious situations. A research-informed attention to the insecure circumstances that are prevalent among older people as well as the strengths and relational world of support of these older persons is fundamental in its ability to contribute to the development of care planning and delivery at all levels from government funding to grass roots supported community centers. Legal knowledge and knowledge about rights for older people should be available for caregivers and older people in order to reduce risks in and to prevent situations of precarity.

As a Swedish researcher, I have carried out ethnographic research in different settings in the United States and Sweden. Since 1999, I have lived and worked in periods in Louisiana. In 2005-2006, I worked for the City of Baton Rouge helping evacuees from New Orleans after Hurricanes Katrina and Rita. I observed the vulnerability of older people in disasters and everyday situations. That is why I wanted to study the strengths and support of older people in Baton Rouge. Although the older participants in the study were not victims of Hurricane Katrina, they too were in the grips of precarious situations, such as threats of loss of housing. The emotional closeness of the older persons and how they opened their homes and resources to displaced family members from New Orleans after Hurricane Katrina had a significant mark on me.

This study analyzes conditions of precarity, strengths and support of older persons in the capital city Baton Rouge in the U.S. state of Louisiana. To understand the social problem of how older people manage insecure living conditions, I focused on the spiritual and psychological strengths of older persons, their social and care support networks as well as at-risk issues to answer the research questions of this study. First, the study asks what older people view as insecure living conditions. Second, the study asks which protective strengths and supportive resources older people use to handle insecure living conditions. Third, the study looks at what meaning older people attribute to protective strengths and supportive resources. Meaning in the context of this study refers to the significance that older people gave to specific outlooks, social relationships, categorizations, cultural symbols, objects and activities in daily life interactions with other people in the culturally defined homes and community sites (cf. Moerman, 1988; Atkinson, 2015).

Based on the interviews and observations of the participants in the community sites for several years, the theoretical construct of precarity was selected to interpret the lived experiences of the older people. The concept of "precarity", a fundamental existential insecurity, can be used to understand the degree to which an older person's overall social circumstances leaves her or him susceptible to risk, potential suffering, and vulnerable and unpredictable conditions (Grenier et al., 2017). Precarity draws attention to unwanted risk and the lack or absence of supportive resources for older people that result from austerity and declining social protection for older people in society. It was Bourdieu (1963) that first presented the theoretical construct of precarity in social science research in his ethnographic description of precarious living conditions in various shanty towns of Algiers in the colonized Algeria in the 1950s. Butler (2004) discussed precarity as differences in human experiences that are socially constructed claiming that the social character of human existence means that humans are dependent on and made vulnerable to others. Precariousness, for Butler, is relational.

Portacolone (2013) has documented conditions of precarity in an ethnography of older people living alone in San Francisco. The precarity experience of the older people included a sense of uncertainty based on a lack of, or having problems in accessing, vital resources. Precarity was 
examined along three levels of analysis: (1) on the micro and personal level of analysis, older people living alone may struggle to perform the household chores handling a deteriorating body, memory problems, and limited income, (2) on the meso and organizational levels of analysis, older persons have challenges understanding the complex context of services and comprehending their eligibility criteria, accessibility, fees, and conditions, and at the same time, they may have to deal with family issues, and (3) the macro level examining the pressure on older solo dwellers of a prevalent ideology that prizes independent behaviors and personal responsibility.

Portacolone et al. (2018) show in a qualitative study of 12 older people living alone with a diagnosis of cognitive impairment that they experienced the following: (1) distress caused by the uncertainty of having cognitive impairment that has an unpredictable course, (2) responsibility for handling their cognitive impairment, and (3) pressures because of a lack of appropriate services to support independent living for older persons with cognitive impairment. Several studies describe the frailty that older people experience including the decline in health and well-being, physical, psychological and social functioning (Becker, 1994; Puts et al., 2009; Warmoth et al., 2016). Research supports that frail older people express a sense of loss related with the decline in overall health and wellbeing (Nicholson et al., 2012). It also suggests that frail older people experience loneliness because of increasing physical impairment (Taube et al., 2016). The experience of decline is disrupted by transitions in illness and health (Grenier, 2012).

Social safety resources for older people in the United States include programs and services available on the local, state and national levels including the Older Americans Act, Medicare and Medicaid. Many of the study participants received benefits from Medicaid. Medicaid is a health insurance program for low-income beneficiaries that is jointly operated by the federal government and individual states. People 65 years of age or older who meet the income and asset limits for their state are eligible for Medicaid. However, in May 2018 thousands of older and/or disabled people in Louisiana including some of the participants faced worsened precarity conditions. The Louisiana Department of Health sent official notifications to 37,000 Medicaid recipients who were older people and/or disabled who could lose their Medicaid benefits that pay for nursing homes and home-based services on July 1, 2018 because of state budget cutting. Nursing home residents suddenly risked being homeless and out on the street. Louisiana would be closing hospitals and reducing mental health treatment for Medicaid recipients to make the current budget proposal work (O’Donoghue, 2018).

Social and care supportive resources were vital for the participants. Supportive resources in this study are viewed as perceptions of older people that they are cared for, receive help from others, and that they are part of supportive social networks. Social and care support can, for instance, come from family caregivers, friends, neighbors, and home-based services. Phillipson (2004) shows how social support networks of older people are directed at a specific purpose such as caring for and helping older persons remain at home by providing various types of assistance.

Participants used spiritual and psychological strengths to manage stressful events and negative emotions. Spiritual strengths describe existential strengths connected to finding meaning and purpose of life and spiritual support from God, church, family and friends. An ethnographic study by Ball et al. (2005) on older African Americans in assisted living facilities in Georgia demonstrates the centrality of spirituality and religion. The participants' lives were filled with church and religion as well as organized church activities and relationships. However, a gap exists in the research on older people regarding their strengths and support in conditions of precarity which this study will take steps to bridge.

Baton Rouge is located eighty miles to the northwest of New Orleans. It is the second largest city in Louisiana with a growing population of 230,058 people as of 2012. In 2010, there were 6,910 older people living in poverty. The priority issues and needs of older people were home delivered meals, homemaker services, knowledge of services and how to apply for services, dental care and eye care. Most of the older people who requested and required formal community-based services 
were on fixed incomes, low income or home bound with little or no family support having to make daily decisions as to either purchasing food or medication (East Baton Rouge Council on Aging, 2015).

\section{Methodology}

The ethnographic fieldwork for this investigation was carried out in a housing complex for lowincome older persons and two senior citizen centers in Baton Rouge between January 2013 and June 2018. I used ethical principles discussed in ethnographic research (Atkinson, 2015; Hammersley \& Atkinson, 2007; Gobo, 2008). Ethics approval was obtained from the studied agencies. Informed consent was obtained from the site coordinators of the senior centers and the housing complex, two family members of older participants and 20 older people that wanted to participate in the study. I conducted the fieldwork aimed to act in an ethically appropriate way and to not publish anything that would cause embarrassment, distress or harm to the participants ensuring mutual trust between myself and them. I actively worked for having a rapport with the participants that required honesty and trust. I used fictitious names for all participants to protect their identities and institutional details and made their comments and behavior confidential.

In the ethnographic fieldwork I described and explained how the participants understood their lives based on participant observation, observational field notes and interviews (Moerman, 1988; Atkinson, 2015). Participant observation means that the researcher establishes a direct relationship with the participants, stays for a period in their natural environment with the purpose of observing and describing their perspectives and practices, interacts with them and participates in their everyday activities. Field notes are the means in ethnographic research to collect observational data. Interviews with the participants were non-recorded and carried out as part of participant observation. I asked open-ended questions in the interviews to obtain descriptions by the participants of their subjective experiences and interpretations of their experiences.

This study used a phenomenological perspective to examine lived experiences of a group predominantly female and African American older people who comprised the study population. Phenomenology analyzes "the world of everyday life" (Schütz, 1970: 72) and focuses on how people recognize and interpret the experiences that describe their everyday reality. The perspective is called phenomenology because it investigates how phenomena or particular experiences are selected and given attention from the constant, flowing stream of experiences of subjectively engaged social actors. Schütz (1970: 72) referred to the everyday life reality as the lifeworld. The lifeworld is shared with other people and is the entire realm of occurrences and experiences of a person which is restricted by objects, taken-for-granted routines, habits, practical knowledge, individuals and occasions that a person comes across in the quest of the practical aims of existence. The subjective reality of an individual is tied to and dependent on the intersubjective shared reality of the self of an individual and other people that is society and which organizes the everyday reality.

The research questions were investigated by conducting a thematic analysis of the data (Grbich, 2013). The analysis focused on key themes from the accounts and practices of the participants. Key themes are patterns in data that emerge and recur in the course of the data collection and analysis while forming a basis for the analytical framework. The analysis specifically focused on courses of actions, arrangements, relationships, references that participants repeatedly made, recurrent terms or phrases, links, ideas, and explained patterns in the data. I created analytical charts exploring emergent themes and patterns and wrote descriptive comments alongside in the margins of the charts as well as attached overarching labels and identified subgroupings. I conceptualized these groupings and linked them to other patterns and themes in literature and theory. To obtain further participant validation, I asked five of the participants to comment on, confirm or reject my fieldnote descriptions and data interpretations. I viewed the older people in the study as coparticipants in research and not objects of observation. I drew contrasts and comparisons of the living conditions held by the participants in Baton Rouge to the older people studied in San Francisco by Portacolone (2013) and Georgia by Ball et al. (2005). 
The single case classic ethnographic study Tuhami. Portrait of a Moroccan by Crapanzano (1980) was an inspiration in my fieldwork. Referring to the method of Crapanzano, I intended the fieldwork to investigate experiences of older people mainly by centering on and documenting experiences of a single, key informant named Rose (her name has been changed to protect her identity) for access to her friendship circles and community relationships. Rose is a Baton Rouge woman, aged 77, with an extensive community-based network in community sites. She has several university degrees and lives in an independent housing complex for low-income older people. This building was a community site where free midday meals were delivered on weekdays.

I carried out in-depth interviews with Rose to comprehend her everyday conceptions of reality, i.e., ways to recognize, interpret and classify her own and others' actions. In documenting the everyday life of Rose in the fieldwork, I let her social activities define the boundaries of the contexts of observation and the fieldwork (cf. Gobo 2008:166). When making field notes in the encounters with the participants, I described what the participants were saying and doing as well as how they characterized and understood what was going on. I wrote observational field notes and engaged in conversations with the participants to understand their relationships and activities. My method was to build relationships to the key informant and her friends based on mutual respect, getting to know each other and demonstrating that I was interested in their lives and to begin conversations with them.

Through knowing Rose, I carried out observations and interviews with older persons in the lobby of the housing complex. The ten participants were four African American men, three African American women and three Caucasian American women with an average age of 77 years that used to spend time in the lobby. The residents of the housing complex were mainly older African Americans. During the fieldwork, I engaged in short conversations in the lobby with two family caregivers of older family members. The housing complex was federally subsidized and situated in an inner-city neighborhood with businesses next to residential housing. The neighborhood was inhabited by primarily African American and Caucasian American residents.

I also observed and interviewed ten older African Americans (nine women and one man with an average age of 76 years) in a senior center in a mostly African American neighborhood (20132014) that Rose visited on a regular basis. This group of older people was later moved to another senior center which was in the same neighborhood as the first senior center and where I continued my data collection (2015-2018). I gained access to the senior centers by following Rose in her everyday activities, being invited by the site coordinator and being introduced to older persons that Rose knew and asking for permission to write about them. The site coordinator of the first senior center continued to lead activities in the second senior center, and the older people in the first senior center continued to attend the activities in the second center. These mainly middle-class older persons, some with college degrees, lived in private homes close to the senior centers. This neighborhood contained wooden and brick housing with residents who were business owners and parents of university educated professionals. The churches and the community center contributed to a sense of community and stability for older people. This inner-city neighborhood was also affected by high crime, violence, poverty and other social problems.

The observational field notes and stories of the participants were collected in diaries which were mainly focused on Rose's everyday activities and life reflections. In the fieldwork I stayed with Rose day and night for approximately one week at a time in the housing complex three times annually and became an active participant in Rose's life history. Rose and I went to the senior center most weekdays and stayed from 9a.m. to $2 \mathrm{p} . \mathrm{m}$. In the afternoons and evenings on weekdays, we stayed for several hours on each occasion in the lobby of the housing complex or in a nearby café or grocery store. On the weekends we attended masses in Catholic churches on Saturdays and Sundays, stayed in the lobby of the housing complex or talked in Rose's apartment. Rose and I view each other as friends. She explained her relationship to me, "You and me are pals. You make me laugh and have fun. You make me happy." 
Rose used to drive to the senior center when I began the study. A few years later, she took buses, taxis or went with friends to the senior center. The site coordinator of the senior center drove her home. In later years due to frailty, Rose attends the meals in the housing complex where she lives and goes less regularly to the senior center in the other neighborhood. When I was away from Baton Rouge during the five years the fieldwork lasted, I talked to Rose on the phone for 10-20 minutes in each telephone conversation 3-4 times weekly. In the telephone conversations, Rose shared stories and commented on my interpretations of the field notes and interviews.

\section{Results}

The findings suggest patterns of precarity, strengths and support of older people on micro, meso and macro levels of analysis.

\section{Conditions of precarity}

On the micro and personal level of analysis, many of the participants were frail and had multiple health issues. They experienced health transitions through deteriorating health, injuries and pressures caused by physical, psychological, social and cultural stressors leaving them vulnerable to episodes of precarity. Many of the participants had memory problems. One older person stated, "I hate choices" and referred to situations when dealing with the health care system. Some of the participants experienced limited mobility including problems of walking, difficulty using public transportation, and the inability to drive.

On the meso and organizational levels of analysis, results suggested that it was mainly participants lacking or having less support from family and friends that experienced most precarity problems. Problems in precarity included unmet needs of care, lack of access to and discontinuity of homebased health care services, Medicaid running out, not knowing about how to or forgetting to apply or reapply for Medicaid, risks of losing Medicaid benefits, problems with prescription and medication access, and forgetting to keep up with medicine renewals and health care visits. Many of the participants experienced problems of not affording health care and medication costs. As a consequence, they expressed that they did not feel good physically or mentally when days passed without having medicines making some of them fall, faint and have problems to communicate with others. Some participants forgot where they put medicines and dropped medicines on the apartment floors without finding them. When they called pharmacies to renew the medicine, the pharmacy staff answered that they should have enough medicine according to what they had received and that they had to wait until the refill date to get more medicine. Various forms of disability affected the ability to deal with the complex service system for older people. Participants with memory problems faced problems in calling and reaching home-based health care services, functioning in daily life and dealing with changes on the micro, meso and macro levels of analysis.

A minority of the participants experienced threats to residential security and risks of being evicted when they did not fulfill the requirements in cleaning their apartments, when they fainted, fell and had problems to walk. One older person at risk of being evicted from the low-income housing complex felt concerned and often stressed about being pressured to keep up the cleaning stating, "People try to do anything to you. The doctor took up for me. I'll pray. I don't want to be in a mess. I'm going to let it go. It hurt me so bad."

On the macro level of analysis, a pattern was that some of the participants in the end of the fieldwork moved away from private homes and the housing complex to nursing homes and faced in the spring of 2018 the risk of being evicted and losing home health care due to Louisiana state cuts in Medicaid funding to those areas. This potential collapse or reduction of the Medicaid support system on the macro level would create a quick, unexpected and negative change in care and support in the worlds of the older people. Emotional responses of the participants to this planned cut included displays of sadness, stress, worries about negative consequences, fear, hopelessness and shock. This possible change in the support to older people and the disabled had the potential to create a range of negative consequences for older people and their families as well as moral issues for decision makers in the Louisiana government. 


\section{Strengths and support of older people in episodes of precarity}

Protective strengths of participants affected by precarity were dependent on the vulnerability to precarity of the participants and levels of care and social support. The analysis identified the following strengths and supportive resources that participants used in episodes of precarity: (1) spiritual faith to maintain hope, find peace of mind, meaning and purpose and deal with existential insecurities, (2) psychological abilities using humor, distraction, relaxation, positive selfperception, self-talk, reflections of situations and wishful thinking, (3) spiritual relationships with friends, church members, and deceased family members and friends in heaven, (4) family support, (5) friendships of love and friendships of helpfulness, (6) care performed by home-based services, (7) involvement in senior center and housing complex community activities, (8) church memberships and activities, and (9) grocery store and café contacts. Spiritual faith and friendships stand out as the most central strengths and supportive resources of the participants.

\section{Spiritual faith to deal with existential insecurities}

A major source of strength of the participants was spiritual faith. Most participants shared and framed human experiences within the religion and spirituality of Christianity which provided responses to human problems of the participants and formed a basis for social cohesion. For most of the participants, spiritual faith and practice played an important part in survival, finding comfort, peace of mind, meaning and a sense of purpose, maintaining hope, and dealing with existential insecurities. One respondent described herself as a "survivor" coping with reality through individual efforts and having a strong spiritual faith believing and praying that God will lead her through life challenges. Another participant stated, "I think about God in everything I do." The participants praised each other for being good Christians and prayed for each other and members of each other's social networks. Participants expressed the centrality in having a direct relationship with Jesus. One older person stated, "When no one else is around I can always talk to Jesus." Participants voiced that spiritual faith provided psychologic benefits including hopeful attitudes about life and illness and enabled them to handle physical health problems and life stresses. The spiritual faith gave participants hopeful feelings, a sense of meaning, comfort and purpose in life.

Religious practices contributed to social support networks for participants. The spiritual faith of participants was reproduced institutionally in senior centers by reading prayers together and discussing topics in the bible. In the senior centers with mainly older African Americans, the local Baptist churches served as the primary centers of group activities for older people in the neighborhood. In the housing complex, most of the participants belonged to Catholic, Baptist and other protestant churches. A few participants were not interested in church activities at all. Both the Baptist and the Catholic participants stressed the importance of giving love to other people and receiving love from others. The older people participated in weekly Baptist and Catholic prayer meetings at the housing complex. Some Catholic participants that were not able to go to church said the rosary in the housing complex described by an older person, "We have a group in the building, a chapel and met at four o'clock. A person led the rosary and the rest of us answered the prayer." Many weekly schedules of the Baptist participants were structured around church activities which were discussed in the two senior centers.

\section{Psychological strengths}

Psychological strengths of the participants included positive self-talk and self-perception, distraction, relaxation, reflections of situations and wishful thinking and the presence and use of humor to laugh and have fun together. Participants had capacities to experience meaning and sense of purpose in stressful life events despite the exposure to risk, insecure living conditions, positive adaption to detrimental living conditions and an openness to learn new coping skills. However, learning new skills and making complex decisions often involved and caused anxiety and stress for the participants. 
The religious community was an important resource promoting friendships between older people. Participants expressed that spiritual faith was a central and constant inner focus and a major source in handling conditions of precarity and a way to create and maintain friendships. One participant gave spiritual recognition to a close friend, "I got a little friend. She cares about people and is a good Christian. She knows Jesus. She takes care of me when I'm sick. She prayed for me." Another participant described her best friend and the decisions she made initiating this friendship: "She is a good Christian and is very sweet. I love her. She has never said nothing bad to me. I chose her. God chose her. I chose to be nice to her. She is nice to me." A participant said that she wanted to "contribute with love to the other older people and the staff." She went to church every day after visiting the senior center to go to communion to in her own words "receive love from God and give love to seniors and staff" in the senior center the next day and added "it makes me and other people smile." The woman said that she liked to socialize face to face with her friends at the senior center. She had two closer friends at the center and telephoned one of them every morning. The woman said that her friend "tells the truth to me and I tell her the truth. I was attracted to her because she is a strong Christian. We love each other and we are glad to see each other at the senior center." These friends shared religious community and spiritual outlooks, values, a sense of what was important, and actively displayed empathy, care and respect for each other.

\section{Spiritual relationships with deceased family members and friends}

Many participants described the importance of having spiritual beliefs, values that can support them in everyday life and individual experiences through the inner spiritual relationship with God and deceased significant others in heaven. They described spiritual relationships with deceased family members, friends and colleagues as sources of comfort and strength. Through spiritual visualization and maintaining spiritual connections to significant others, the participants dealt with losses and grief of loved ones and others, adjusted to life changes without the loved ones and thought about positive memories of deceased significant others. They said that they looked forward to meeting them in heaven. One participant said, "I'm so happy to have a life after death. I will live forever. The meaning of life is to go to heaven. I visited heaven with my mind, with my spirit. God helped me to see my daddy. I talk to my granny and my aunt can talk to granma. Her mama is in heaven. I love them all. They are good and love good." When one older person talked to other older people about meeting family and friends in heaven, they shared stories about family members and friends that had passed away.

\section{Family support}

Participants expressed gratitude to receive support from their families including having family members visiting and calling older family members for them to maintain a stable and secure daily life. One participant explained, "I'm glad to have my people. I feel confident with the support of my family." Family caregivers that I met in the lobby of the housing complex described dilemmas when caring for older family members. One central dilemma was the continuity of care. When family was present, it was the family that facilitated the continuity of care. If they were not there it made the older family members more vulnerable. Some of the older people in the study lacked family support.

Older family members needed routines. It was common that they got out of their routines of taking medicines, drinking, eating, sleeping and taking care if their hygiene. They could oversleep and miss meals and times to take medicine. Sometimes when they got out of routines, family caregivers had to retrain older family members reminding them what to do in the routines of daily life or arrange the homes of older family members in ways that made it easier for them in their daily lives. When telecare communication was not working out with older family members it was vital that family caregivers arranged to be there physically with older family members to provide family 
support face to face and get older family members back into the routine to take medicines, eat and drink. When the daily routines did not work out for older family members family caregivers talked about plans and made decisions to help older family members move to assisted living or nursing homes.

Sometimes participants moved into the homes of family caregivers. Challenges family caregivers faced in the new situation of living together with older family members were in the words of a family caregiver, "Arranging it, taking care of the medicines, arranging what do I do when she needs a ride to the appointment, scheduling the appointment so that her ride will be able to pick her up. Should I encourage her to walk without a walker? I think it's good she is eating a lot. If she didn't eat enough I would be worried about it. After I moved in with her she started to eat more and more variety. She seems a lot happier. She had problems remembering. Now she remembers more and doesn't forget what she was saying." From the perspectives of the older family members, being in the arms and eyes of family caregivers made a difference in securing safety monitoring, and eating, drinking and medication routines for older family members. Family caregivers expressed that they felt that the care of older family members was occupying an increased part of their daily lives making them want older family members to move into nursing homes or assisted living places. Older family members often displayed resistance, insecurity and fears about moving into nursing homes or assisted living places.

\section{Friendships between older people}

The participants described friendships as personal relationships based on caring for one another. They described friendships as close-knit and deep social relationships, mutual care and love and reciprocated acknowledgments of this care and love. Friendships helped the participants in senior centers to meet their needs for social recognition and belonging in the local community and were ways to build social support and resist precarity. Gender differences I observed were the closely intimate relationships of female friends sharing secrets and fears and repeatedly reassuring each other as compared to male friends interacting in a group of 3-4 men having fun sharing stories and talking about memories, sports, cars and practical issues.

Friends and family members, mainly the children and siblings of the older people, were the first people participants turned to when they experienced conditions of precarity and had problems including the risk that their Medicaid benefits to pay for home health care services may get cut, residential insecurity, lacking monetary resources, and having mental health and physical health problems. Receiving social and care support from friends and family caregivers allowed participants to build support relationships, handle stress, feel hope and give them a sense of intimacy. In interviews with participants, two main domains of friendships were distinguished: (1) friendships of love and (2) friendships of helpfulness. The two forms of friendship seem to involve a concern for the friend for her or his and for the older person's own happiness, health, safety and mobility.

\section{Friendships of love}

The first friendship type was friendships of love. Participants expressed that friendships of love provided encouragement, reassurance and mutual support based on social relations of love, trust, respect, empathic understanding and confiding personal problems during difficult times. These intimate and deeply meaningful relationships offered socioemotional support. The relations between friends of love were strong and carried a connotation of deep affective relations that created positive emotions and motivation to cope with life concerns. Friendships of love were longterm and about life meaning contributing to that older people even could move into each other's homes if it was necessary.

When participants described friendships of love, several patterns recurred. A common pattern was social trust confiding personal problems sharing fears, hopes and secrets. Other patterns were care, 
loyalty, having fun in joking relationships, and intimacy. They stressed the importance of being loyal to each other. One participant talked about what made her happy, "My friend Anne laughs and she likes to have fun which makes me feel happy. She is a good Christian. She doesn't tell my business. I used to see her at the center to talk about her family." Friendships of love between participants were described as intimate conversations about private matters without disclosing what was talked about to other people. One woman described her friendships of love, "Alice and Gloria are my two best friends. They really love and care for me all the time." These descriptions suggested that the women shared life experiences and supported each other.

\section{Friendships of helpfulness}

The second friendship type was friendships of helpfulness providing practical help for the participants. One participant described a friend that drove her to places she needed to go to: "When it's important I can call him. I can ask John anything and he will do it. It was raining and I wanted to go to the bank. Another lady needed to go. He took her too. I can go and knock and tell him. I'll be in the lobby. I tell him that I only call him when it's important. When I need help he will help me." One participant had a friend in the senior center site coordinator and talked positively about their close friendship: "She is my friend and is nice. When you really need something, she will get it for you, for example, when I need medicine, she will call about the medicine and get the medicine for me. She takes me to the doctor's office, the pharmacy and the dentist. Miss Phillips (the senior center site coordinator) helped me as much as Anne (her best friend at the senior center). I have celebrated Christmas, New Year and Thanksgiving with Miss Phillips and her family."

\section{Community-based supports and services for older people}

Supportive networks and community-based support services for the participants included senior centers, nutritional sites, primary care, the home health care agency for older people and the disabled called Merakey, churches, grocery stores and cafés. The following sections describe the most commonly used community-based supports and services and explain what they mean to the participants.

\section{Senior centers and the housing complex}

A senior center can be described as a type of community center and social order where older people assemble and socialize to satisfy social, emotional, intellectual, physical and spiritual needs. The senior centers provided social arenas in which participants created friendships and other relationships, eat and talk and give social support to each other. Social support relationships were created, and social resources accumulated mainly through by being active in the social contacts and activities in the senior centers. The participants emphasized the following six main functions of senior centers: (1) free lunches, (2) friendships and other social relationships, (3) spiritual faith and practice, (4) a place where older people can belong through shared activities, (5) music and dance for meaning and as emotional expressions, and (6) exercise. Hot meals were served to older people at the two senior centers and the nutritional site and housing complex.

\section{Primary care and health care services for older and/or disabled people}

The participants visited primary care services on a regular basis to receive help with many of their basic health needs. Another care provider of older and/or disabled people was Merakey. Many participants stated that Merakey was an important agency for them by providing health care services and helping them to remain independent in the apartments of the housing complex, in private homes offering home health care services, helping with medication prescription, mental health services, and personal assistance services. Nurses, nurse practitioners and social workers from the agency visited the apartments of participants in the housing complex and private homes of participants and gave shots, medicines, checked the blood pressure and provided other services. 
The social workers of Merakey counselled participants and helped them to fill out forms for, e.g., health care supports and transports. Merakey was also an advocate for the older people in collaboration with other agencies in the community empowering participants to stand up for their rights and to keep their homes when their residential status was at risk.

\section{Church memberships and activities}

Churches provided venues for the older people to participate in religious services and social events. Participants had access to churches by driving, going with family members and having church members pick them up to provide transportation to church. Most of the older people participated in weekly church services and spent a large amount of their awake time talking about spiritual matters. When participants became frail and homebound, they often had trouble staying connected with formal religious support systems. They kept on praying in their homes. Sometimes church members visited participants in their homes to pray together. Participants also watched live or recorded masses and services on the television.

\section{Grocery store and café contacts}

Participants in the housing complex walked to a nearby combined grocery store and café which one respondent described, "It's a nice place to meet people. I meet old friends, a sister of an old friend and a lawyer, people I met in my life." One participant talked about the staff of this café, "They are interested in me and my welfare. I love them people. I talk to them about people who are stressful to me." Not all grocery stores and cafés were financially accessible for the participants. Gentrification was visible in some parts of the residential neighborhood of Rose excluding her and other participants to a grocery store that they previously had been going to for decades. This store had recently been transformed into an exclusive grocery store with more affluent customers who could afford higher food prices. The participants expressed feelings of missing going to this store.

\section{Conclusion}

This study has been concerned with understanding how older people experienced and managed conditions of precarity. The sample is novel in that it focused primarily on the lifeworlds of older African American women. The concept of precarity is novel as well. The pattern of results suggests that the home-based services were not sufficient to prevent and reduce precarity for older people because of a lack and discontinuities of these services. It is important to recognize that the participants experienced both long-term and occasional moments of precarity, often expressed as uncertainty, where daily living became precarious and their support was threatened. Spiritual faith and friendships stand out as the most central strengths and supportive resources in older people's lives to manage daily challenges. Within this context a principal focus of future studies can be to explore funding patterns in Medicaid assisted living facilities, to community centers with programs for older people and independent living apartment complexes for older persons.

The older people in Baton Rouge experienced similar precarious living conditions as described by Portacolone in the ethnography of older people in San Francisco. Older participants in both cities experienced uncertainty based on a lack of or having problems in accessing community resources. Participants in both places struggled to perform household chores managing deteriorating bodies, memory problems, and limited incomes, and understanding the complex context of supports and services. However, the participants in Baton Rouge experienced threats and risks of a collapsing support system for older people and disabled Medicaid recipients which could result in evictions for thousands of older people from nursing homes and losing benefits to pay for home health care services. Because Baton Rouge is a capital city older people had a chance to make their voices heard and protest at the state capitol building against planned measures that were negative to them.

Consistent with research by Ball and others on assisted living for older African Americans in Georgia, this study stressed the centrality of spirituality and religion for the older people in Baton 
Rouge demonstrating that participants were reared in the church and religion and organized church activities as well as relationships were central in the older persons' lives in Georgia and Louisiana. What was unique about the participants in Baton Rouge was that they did not only stress the importance of church activities, but also had direct spiritual relationships with God and deceased family members and friends as primary resources for spiritual strength and survival.

\section{Implications for practice}

A significant implication of the results is the importance of studying the combined relationship of protective strengths and supportive resources of older people to deal with conditions of precarity. This study adds to the literature about precarity among community-based older people by identifying conditions of precarity, ways to deal with precarity and suggesting policy implications. Policy implications of this investigation are that ongoing care support by homebased health care services and medication access without gaps are needed to reduce and protect against precarity of older people. Social policy and key priority recommendations of the findings are as follows: (1) The government can provide funding to simplify for older people to have personal assistants and promote friendships between older people through programs for older people peers in community centers. (2) It is crucial to create and maintain ongoing presence of home-based health care services for older people to maintain self-care, health care, medication access, support and perform activities of daily living. (3) Home health care staff should be available to older people by telephone to make appointments and home visits. (4) One of the main problems is that older people have problems walking. Communities can provide shuttle services for older people to go to the community centers. More resources are needed to home health care staff to drive older people to appointments or help them when waiting for the Medicaid van, get into the Medicaid van rides, stay with them on the appointment and return with them on the van. (5) It is vital to maintain residential security and prevent eviction and homelessness of older people supporting older persons in place or helping them to be relocated to new homes in case they are evicted to maintain long-term health, care and stability for older people. One measure is to have post-eviction care specifically designed for older people through starting and funding shelters to house and feed older people. These shelters should provide help to older people to do paper work and make calls to sign up for new housing. Another measure is to have funding to provide legal services for older people to prevent them from being evicted and have informational campaigns to inform older people, leaders and boards of senior housing complexes about the legal rights of older persons. This could be achieved by having campaigns for the whole community including TV commercials and Internet based ads and films. More working groups should be formed to discuss legal issues of older persons and to help apply human rights norms to situations of precarity held by older people.

One of the main arguments here regarding public policy is that older people should be able to stay because the buildings for low-income seniors receive federal funding. One of the most poignant significances of having conducted this study is the exposure of that the threat of eviction for older persons in low-income housing exists even with the presence of federal funding for these buildings. It is crucial to identify community strategies to actively protect vulnerable older people. Some older persons in the study experienced a constant precarity and it was not sufficient to remove precarity through informal networks. The findings suggest that ongoing state funding and support by home-based services are necessary to support frail older people in precarious living conditions to survive and handle stressful life events by reducing vulnerability and enhancing strengths and supportive resources of older people.

Another component in play when discussing precarity and strengths and support of older people calls for an analysis of precarious living conditions and resilience strengths of older persons in South Louisiana who are living in a cyclical crisis environment having to recover and maybe relocate associated with regular floods and hurricanes. Older people in South Louisiana can use a lifetime of disaster resilience strengths helping them to understand, assess, manage and survive the emotionally distressing experiences and challenges that arise from disasters, but they also need 
ongoing help from family caregivers, friends and community-based services for older persons to manage disaster circumstances that is recipient designed for their needs and concerns.

\section{References}

Atkinson, P. (2015). For Ethnography. London: Sage Publications.

Ball, M. M., Perkins, M. M., Whittington, F. J., Hollingsworth, C., King, S. V., \& Combs, B. L. (2005). Communities of Care. Assisted Living for African American Elders. Baltimore: The John Hopkins University Press.

Becker, G. (1994). The Oldest Old: Autonomy in the face of frailty. Journal of Aging Studies, 8(1), 59-76.

Bourdieu, P. (1963). Travail et travailleurs en Algérie. Paris and The Hague: Mouton (with Alain Darbel, Jean-Paul Rivet, and Claude Seibel).

Butler, J. (2004). Precarious life: The powers of mourning and violence. London: Verso.

Crapanzano, V. (1980). Tuhami. Portrait of a Moroccan. Chicago: The University of Chicago Press.

East Baton Rouge Council on Aging. (2015). Area Agency on Aging Four-Year Area Plan. Retrieved from http://www.ebrcoa.org/Images/Interior/area-Plan-2015-2019-finalcopy.pdf?p1=9799 [Accessed May $\left.12^{\text {th }}, 2018\right]$.

Gobo, G. (2008). Doing Ethnography. London: Sage Publications.

Grenier, A. (2012). Transitions and the Lifecourse: Challenging the constructions of 'growing old'. London: Policy Press.

Grenier, A., Phillipson, C., Laliberte Rudman, D., Hatzifilalithis, S., Kobayashi, K., \& Marier, P. (2017). Precarity in late life: Understanding new forms of risk and insecurity. Journal of Aging Studies, 43, 9-14.

Grbich, C. (2013). Qualitative Data Analysis. An Introduction. $2^{\text {nd }}$ ed. London: Sage.

Hammersley, M. \& Atkinson, P. (2007). Ethnography: Principles in Practice, 3rd ed., London: Routledge.

Moerman, M., (1998). Talking culture. Ethnography and conversation analysis. University of Pennsylvania Press.

Nicholson, C., Meyer, J., Flatley, M., \& Holman, C. (2012). The experience of living at home with frailty in old age: A psychosocial study. International Journal of Nursing Studies, 50(9), 11721180.

O’Donoghue, J. (2018). 'Louisiana following through with warnings to 37,000 Medicaid recipients'. Retrieved

from 
http://www.nola.com/politics/index.ssf/2018/05/louisiana_nursing_home_notices.html [Accessed May 12, 2018].

Phillipson, C. (2004). Social networks and social support in later life. In G. Phillipson, G. Allan, \& D. Morgan (Eds.), Social Networks and Social Exclusion: Sociological and Policy Perspectives. (pp. 142-161). Aldershot: Ashgate.

Portacolone, E. (2013). The notion of precariousness among older adults living alone in the U.S., Journal of Aging Studies, 27, 166-174.

Portacolone, E., Rubinstein, R. L., Covinsky, K. E., Halpern, J. \& Johnson, J. K. (2018). The Precarity of Older Adults Living Alone With Cognitive Impairment, The Gerontologist, gnx193.

Puts, M. T. T., Shekary, N., Widdershoven, G., Helders, J., Deeg, D., \& Dorly, J. H. (2009). The meaning of frailty according to Dutch older frail and non-frail persons. Journal of Ageing Studies, 23(4), 258-266.

Sabatino, C. (2018). Human Rights of Older People. American Bar Association. https://www.americanbar.org/groups/law_aging/publications/bifocal/vol_37/issue_2_decemb er2015/2015-human-rights-older-persons-international/ [Accessed December $2^{\text {nd }}, \overline{2018}$ ].

Schütz, A. (1970). On Phenomenology and Social Relations: Selected Writings. In H. Wagner. (Ed.), Chicago: University of Chicago Press.

Taube, E., Jakobsson, U., Midlov, P., \& Kristensson, J. (2016). Being in a Bubble: The experience of loneliness among frail older people. Journal of Advanced Nursing, 72(3), 631-640.

Warmoth, K., Lang, I., Phoenix, C., Abraham, C., Andrew, M. K., Hubbard, R. E., \& Tarrant, M. (2016). Thinking you're old and frail: A qualitative study of frailty in older adults. Ageing and Society, 36, 1483-1500. 